\title{
Fused PET/CT or CECT in Post-Therapeutic Assessment of Colorectal Cancer: A Study of the Efficacy of the Modality of Choice among Egyptian Patients
}

\author{
TALAAT A. HASSAN, M.D. and AHMED A. BAZ, M.D. \\ The Department of Radiology, Faculty of Medicine, Cairo University
}

\begin{abstract}
Background: One of the most common cancers, colorectal cancer accounts for several tumor-related mortalities; its high recurrence rates either as a local recurrence of the disease or as a distant metastatic disease (up to 35-40\%) have been reported in the treated patients within the first two years following surgery. There has been heated debate over the modality of choice for imaging of the recurrent colorectal cancer.
\end{abstract}

Aim of Study: This study investigates the diagnostic performance of fused Positron Emission Tomography/ Computed Tomography (PET/CT) in comparison to ContrastEnhanced Computed Tomography (CECT) as a follow-up and restaging imaging tool for post-therapeutic colorectal cancers among Egyptian patients.

Subjects and Methods: Data were collected from 84 Egyptian patients ( 26 females and 58 males, age ranges from 35 to 80 years) who were treated from colorectal cancers. They were referred to a private imaging center for evaluation of their disease recurrence by fused PET/CT.

Results: Disease recurrence was categorized as operative bed recurrence/residual (incomplete therapeutic response), nodal, and distal metastases. The site of the tumor recurrence was predominantly seen in the rectosigmoid region in 31 patients $(36.9 \%)$, followed by the ascending colon where it was present in 13 patients $(15.4 \%)$, then the transverse colon as depicted in 9 patients $(10.7 \%)$; the descending colon recurrence was noted in 6 patients $(7.1 \%)$, and the caecal recurrence existed in only one patient (1.3\%).

With reference to the gold standard (the histopathology reports with a correlation to the clinical and the follow-up examinations for the patients as well as the tumor markers (CEA) levels), the fused PET/CT had sensitivity, specificity, positive predictive value, negative predictive value, and an overall accuracy of $93.33 \%, 83.33 \%, 93.33 \%, 83.33 \%$ \& $90.48 \%$ respectively as compared to CECT $(73.33 \%, 58.33 \%$, $81.48 \%, 46.67 \%, 69.05 \%$ respectively).

Conclusion: Our findings indicate that fused PET/CT is more effective than the CECT regarding the detection of operative bed recurrent disease and incomplete therapeutic

Correspondence to: Dr. Talaat A. Hassan, E-Mail: talaathassan38@yahoo.com responses. PET/CT may also offer a cost-effective wholebody scan for restaging of the recurrent diseases through an accurate detection of the nodal and distant metastases.

Key Words: PET-CT-CECT-Colorectal cancer.

\section{Introduction}

COLORECTAL cancer is one of the most common cancers that affect human beings and account for several tumor-related mortalities; high recurrence rates either as a local recurrence of the disease or as a distant metastatic disease (up to $35-40 \%$ ) have been reported in the treated patients within the first two years following surgery. However, it may be potentially cured if it is early detected, and the curative measures are taken $[\mathbf{1 , 2}]$.

Metastatic disease in colorectal carcinoma can occur anywhere in the body, but it often has nodal, hepatic, and pulmonary predilection; thus, the whole-body screening for the metastatic disease is considered a critical step for the staging of the primary disease and restaging of the recurrent one $[3,4]$.

Recently, several diagnostic tools have been implemented for the follow-up of the treated colorectal cancers to assess the recurrent and the metastatic diseases: These include laboratory investigations (e.g., tumor markers and optical colonoscopy) and the conventional diagnostic imaging modalities (e.g., ultrasound, Computed Tomography (CT) and Magnetic resonance imaging (MRI). However, these modalities might lack high sensitivity and specificity $[\mathbf{3 , 4}]$.

\section{List of Abbreviations}

PET/CT : Positron Emission Tomography/Computed CECT Tomography.

SUV : Contrast-Enhanced Computed Tomography.

FDG : Standardized Uptake Value. : Fluoro-2-Deoxy-d-Glucose. 
Through the assessment of the metabolic activity of the tumor tissues, functional imaging is considered a well-established imaging technique using the glucose analogue [1 8F] Fluorodeoxyglucose-Positron Emission Tomography (FDG-PET) for detection of colorectal cancers and the distant metastatic deposits, yet the poor spatial resolution of FDG-PET was a limitation. To overcome this limitation, hybrid imaging techniques have emerged to provide more enhanced, anatomical details and integrated imaging modalities that may improve the detection of tumor recurrences in treated colorectal cancers and distant metastases [5-12]. The literature has presented the fused PET/CT as both cost-effective and accurate diagnostic modality for detection of the colorectal cancer recurrence [13-15].

\section{Aim of work:}

To investigate the diagnostic performance of fused Positron Emission Tomography/Computed Tomography (PET/CT) compared to ContrastEnhanced Computed Tomography (CECT) in the follow-up assessment and restaging of the patients with treated colorectal cancers through measurements of the sensitivity, specificity, positive predictive value, negative predictive value, and overall accuracy.

\section{Subjects and Methods}

Participants: 84 patients were enrolled in this retrospective study. They were referred to a private imaging center for their assessment by fused $\mathrm{PET} / \mathrm{CT}$ and the evaluation of their treatment response in the period from November 2017 till July 2019; they were cases of treated colorectal cancers. The patients' ages ranged from 35 to 80 years with a mean age $(58.73 \pm 11.29$ years) (Table $1)$. They were 26 females ( $31 \%$ of cases) and 58 males (69\% of cases) (Table 2 ).

Inclusion criteria: Cases of colorectal malignancies who had curative (surgical or endoscopic) resection, chemotherapy, radiotherapy or any combination of them were included in the current study (Table 3).

Exclusion criteria: The patients who had a benign colorectal neoplasm or had colorectal malignancy without any previous treatment were excluded.

The protocol was reviewed and approved by the Local Ethics Committee.

\section{Procedure:}

The patients were instructed to fast for 6 hours before the examination and they were well- hydrated. Blood glucose level was measured before the examination in all patients and was within normal ranges (a maximum limit was $150 \mathrm{mg} / \mathrm{dl}$ ) before [fluorine-18] Fluoro-2-Deoxy-d-Glucose (FDG) injection. $0.22 \mathrm{mCi} / \mathrm{kg}$ of (18F-FDG) was injected and then the patients relaxed for 45 minutes (considered as the uptake period). The PET/CT system using a multi-detector (sixteen detectors) CT machine (GE, Discovery IQ, USA) was employed to examine the patients. For the sake of attenuation correction and image fusion, low dose of non-contrast enhanced CT images were taken. The examination levels were extending from the nose to the mid-thigh levels for PET scans. The total acquisition time for the integrated PET/CT scan was nearly 30 minutes.

All patients underwent CECT examination in another imaging center before doing PET/CT and they brought their CECT films for evaluation.

Data management and analysis were performed using the Statistical Package for Social Sciences (SPSS) vs. 21. The sensitivity, specificity, Positive Predictive Value (PPV), Negative Predictive Value (NPV), and accuracy of the PET/CT in the diagnosis of recurrent colorectal cancers were calculated using the standard definitions [16]

\section{Data analysis:}

Through special workstations, the reconstruction of PET image data sets using the CT data for attenuation correction was done and co-registered multiplanar images were obtained using special software. An experienced radiologist (5 years of experience in the PET/CT imaging) did interpretation of the examination. The CT, PET, and the fused PET/CT images were interrogated by visual assessment that considered the hepatic parenchyma as a standard reference for the same patient, and by measuring the Standardized Uptake Value (SUV), as semi-quantitative assessment. SUV was automatically calculated using the equation for SUV measurement SUV=(Dose in tissue/injected dose) $\mathrm{X}$ patient weight, where tissue tracer activity was in microcuries per gram, injected radiotracer dose was in microcuries, and the patient weight was in kilograms [17]

\section{CECT data analysis:}

Depictions of colonic soft-tissue masses or mural thickening with or without signs of infiltration of the surrounding peri-colonic tissues were considered as signs of malignancy. A size-based threshold of $10 \mathrm{~mm}$ (short axis) for the malignant lymph nodes was considered. The central breaking down (necrosis) was used as a sign of malignancy; 
however, a preserved fatty hilum and matrix calcification of a lymph gland was considered as signs of benignity. Malignant hepatic focal lesions were reported when hypodense lesions were seen either with or without marginal contrast enhancement and the other imaging criteria were suggestive of metastatic nature. For pulmonary nodules, any pulmonary nodule without calcification was considered as a malignant one while, the calcified pulmonary nodule was considered as a benign nodule.

\section{PET/CT data analysis:}

The colonic soft tissue masses or mural thickenings were considered as a positive recurrence if their FDG uptake was higher than the background activity. The positive hepatic focal lesions were considered if their FDG uptake was more than or equal to that of the rest of the hepatic parenchyma, whereas negative lesions were reported if their FDG uptake was lower than that of the rest of the liver parenchyma. The pulmonary nodules that had a size of $5 \mathrm{~mm}$ were considered as positive for malignancy if their FDG uptake was exceeding the mediastinal blood pool, yet a metastatic disease could not be completely ruled out in the pulmonary nodules that were less than $5 \mathrm{~mm}$. If the bone marrow exhibited an obvious multifocal FDG avidity, it was considered as positive for infiltration. However, a diffuse uptake pattern in reactive bone marrow hyperplasia after chemotherapy could

Table (1): Demonstrating the range of age in years.

\begin{tabular}{ll}
\hline Age & \\
\hline Mean & 58.73 \\
Standard Deviation (SD) & 11.29 \\
Minimum & 35 \\
Maximum & 80 \\
\hline
\end{tabular}

Table (2): Demonstrating the distribution of patients according to sex.

\begin{tabular}{lcc}
\hline Sex & Frequency & Valid percent \\
\hline Female & 26 & 31 \\
Male & 58 & 69 \\
\hline Total & 84 & 100 \\
\hline
\end{tabular}

simulate or mask a diffuse marrow infiltration; in such case, an appropriate correlation to the patient history was needed. A few weeks (3-4 weeks) after completion of the chemotherapy were enough for the physiological marrow activity to abate. The positivity of the peritoneal seeding or masses was considered when their FDG uptake was more than that of the background activity.

\section{Results}

Eighty-four patients were included in the current study retrospectively (58 males and 26 females).

Recurrent disease was present in 60 patients out of $84(71.4 \%)$ Figs. $(1,4,6)$ but did not occur in the other 24 patients $(28.6 \%)$ Fig. $(2,3,5)$. Recurrent disease was categorized as operative bed recurrence/residual Fig. (1), metastatic lymph nodes Figs. $(1,4)$, and distant metastatic lesions Fig. $(1,4,6)$ (Table 4).

The site of the tumor recurrence was predominantly seen in the rectosigmoid region in 31 patients (36.9\%), followed by the ascending colon where it was present in 13 patients $(15.4 \%)$, then the transverse colon as depicted in 9 patients $(10.7 \%)$; the descending colon recurrence was noted in 6 patients $(7.1 \%)$, and the caecal recurrence existed in only one patient $(1.3 \%)$ as presented in (Table $5)$.

Table (3): Showing the treatment methods for the patients in the study with a demonstration of their number (No.) and percent (\%).

\begin{tabular}{lcc}
\hline Treatment method(s) & $\begin{array}{c}\text { No. of } \\
\text { patients }\end{array}$ & $\begin{array}{c}\% \text { of } \\
\text { patients }\end{array}$ \\
\hline $\begin{array}{l}\text { - Operative and/or endoscopic } \\
\text { intervention (Only) }\end{array}$ & 24 patients & $28.6 \%$ \\
- Chemotherapy (Only) & 18 patients & $21.4 \%$ \\
- Radiotherapy (Only) & None & $0 \%$ \\
- Operative and/or endoscopic & 12 patients & $14.3 \%$ \\
intervention in addition to & & \\
chemotherapy and radiotherapy & & \\
- Operative and/or endoscopy in & 36 patients & $43.0 \%$ \\
$\begin{array}{l}\text { addition to chemotherapy } \\
\text { - Chemotherapy and radiotherapy }\end{array}$ & 4 patients & $4.7 \%$ \\
\hline
\end{tabular}


Table (4): Patterns of tumor recurrence/residual, lymph nodes (nodal), and distant metastasis (mets.) in the study with their number (No.) and percent (\%).

\begin{tabular}{|c|c|c|}
\hline Patterns & $\begin{array}{c}\text { No. of } \\
\text { patients }\end{array}$ & $\begin{array}{c}\% \text { of } \\
\text { patients }\end{array}$ \\
\hline I- Operative bed recurrence/residual: & 60 patients & $71.4 \%$ \\
\hline a- Operative bed recurrence/residual & 26 patients & $30.9 \%$ \\
\hline $\begin{array}{l}\text { b- Operative bed recurrence/residual } \\
\text { with nodal mets. }\end{array}$ & 8 patients & $9.5 \%$ \\
\hline $\begin{array}{l}\text { c- Operative bed recurrence/residual } \\
\text { with distant mets. }\end{array}$ & 4 patients & $4.7 \%$ \\
\hline $\begin{array}{l}\text { d- Operative bed recurrence/residual } \\
\text { with nodal and distant mets. }\end{array}$ & 22 patients & $26.2 \%$ \\
\hline II- Lymph nodes: & 30 patients & $35.7 \%$ \\
\hline a- Abdominal & 22 patients & $26.2 \%$ \\
\hline b- Mediastinal & 6 patients & $7.14 \%$ \\
\hline c- Cervical & 3 patients & $3.6 \%$ \\
\hline III- Distant metastasis: & 26 patients & $30.9 \%$ \\
\hline a- Liver & 22 patients & $26.2 \%$ \\
\hline B- Lung & 11 patients & $13.1 \%$ \\
\hline C- Peritoneum & 3 patients & $3.6 \%$ \\
\hline D- Bone & 2 patients & $2.4 \%$ \\
\hline E- Atypical sites & 1 patients & $1.2 \%$ \\
\hline
\end{tabular}

Table (5): Showing the site of local tumor recurrence with a demonstration of the number (No.) and the percent (\%) for each site.

\begin{tabular}{lcc}
\hline Site & $\begin{array}{c}\text { No. of } \\
\text { patients }\end{array}$ & $\begin{array}{c}\% \text { of } \\
\text { patients }\end{array}$ \\
\hline Recto-sigmoid & 31 patients & $36.9 \%$ \\
Ascending colon & 13 patients & $15.4 \%$ \\
Transverse colon & 9 patients & $10.7 \%$ \\
Descending colon & 6 patients & $7.1 \%$ \\
Cecum & 1 patient & $1.2 \%$ \\
\hline
\end{tabular}

The reference gold standard in our study was the histopathology results with a correlation to the clinical and the radiological follow-up assessments as well as the tumor markers (CEA) if they were available. With reference to the gold standard, the fused PET/CT (for the local tumor recurrence/ residual) had sensitivity, specificity, positive predictive value, negative predictive value and an overall accuracy of $(93.33 \%, 83.33 \%, 93.33 \%$, $83.33 \%$ \& $90.48 \%$ ) respectively with $95 \%$ confi- dence interval (95\% CI) $(83.8 \%$ to $98.15 \%, 62.62 \%$ to $95.26 \%, 85.09 \%$ to $97.17 \%, 65.61 \%$ to $92.91 \%$ \& $82.09 \%$ to $95.80 \%$ ) respectively, while the CECT for the local tumor recurrence/residual had sensitivity, specificity, positive predictive value, negative predictive value and an overall accuracy of $(73.33 \%, 58.33 \%, 81.48 \%, 46.67 \%, 69.05 \%)$ respectively with $95 \%$ CI $(60.34 \%$ to $83.93 \%$, $36.64 \%$ to $77.89 \%, 72.79 \%$ to $87.86 \%, 33.80 \%$ to $60.0 \%$ \& $58.02 \%$ to $78.69 \%$ ) respectively (Tables 6-8).

Table (6): Patterns of local tumor recurrence/residual with reference to the gold standard, by PET/CT in comparison to CECT with a demonstration of the number (No.), percent (\%) of the patients.

\begin{tabular}{|c|c|c|c|c|}
\hline $\begin{array}{l}\text { Local residual/ } \\
\text { recurrence }\end{array}$ & \multicolumn{2}{|c|}{$\begin{array}{l}\text { Positive by the } \\
\text { gold standard }\end{array}$} & \multicolumn{2}{|c|}{$\begin{array}{l}\text { Negative by the } \\
\text { gold standard }\end{array}$} \\
\hline \multicolumn{5}{|l|}{ I- By PET/CT: } \\
\hline Positive & 56 patients & $66.6 \%$ & 4 patients & $4.7 \%$ \\
\hline Negative & 4 patients & $4.7 \%$ & 20 patients & $23.8 \%$ \\
\hline \multicolumn{5}{|l|}{ II- Bу CECT: } \\
\hline Positive & 44 patients & $52.4 \%$ & 10 patients & $11.9 \%$ \\
\hline Negative & 16 patients & $19.05 \%$ & 14 patients & $16.6 \%$ \\
\hline
\end{tabular}

Table (7): Accuracy measures for local residual/recurrence as detected by PET/CT with a demonstration of the $95 \%$ confidence interval $(\mathrm{CI})$.

\begin{tabular}{lcc}
\hline Statistical parameter & Value & $95 \%$ CI \\
\hline Sensitivity & $93.33 \%$ & $83.8 \%$ to $98.15 \%$ \\
Specificity & $83.33 \%$ & $62.62 \%$ to $95.26 \%$ \\
Positive predictive value & $93.33 \%$ & $85.09 \%$ to $97.17 \%$ \\
Negative predictive value & $83.33 \%$ & $65.61 \%$ to $92.91 \%$ \\
Accuracy & $90.48 \%$ & $82.09 \%$ to $95.80 \%$ \\
\hline
\end{tabular}

Table (8): Accuracy measures for operative bed residual/ recurrence as detected by CECT with a demonstration of the $95 \%$ confidence interval (CI).

\begin{tabular}{lcc}
\hline Statistical parameter & Value & $95 \%$ CI \\
\hline Sensitivity & $73.33 \%$ & $60.34 \%$ to $83.93 \%$ \\
Specificity & $58.33 \%$ & $36.64 \%$ to $77.89 \%$ \\
Positive predictive value & $81.48 \%$ & $72.79 \%$ to $87.86 \%$ \\
Negative predictive value & $46.67 \%$ & $33.80 \%$ to $60.0 \%$ \\
Accuracy & $69.05 \%$ & $58.02 \%$ to $78.69 \%$ \\
\hline
\end{tabular}


$9 / 2018$
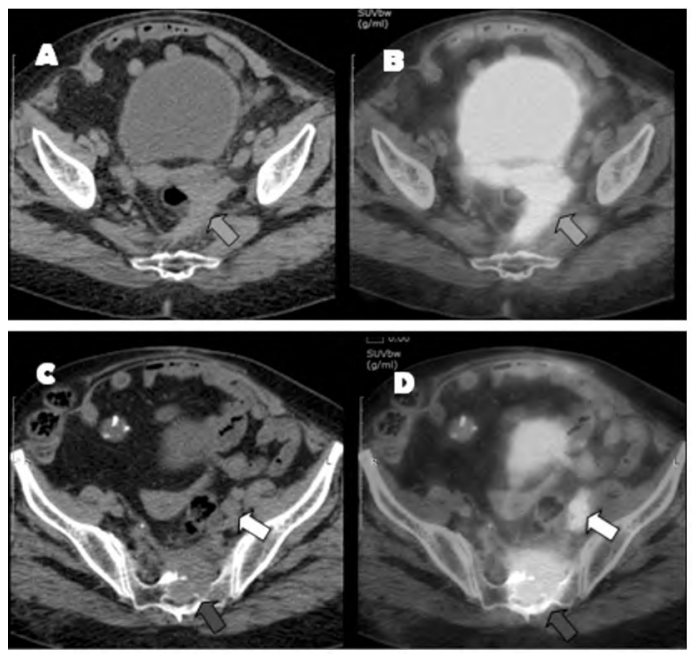

$12 / 2018$
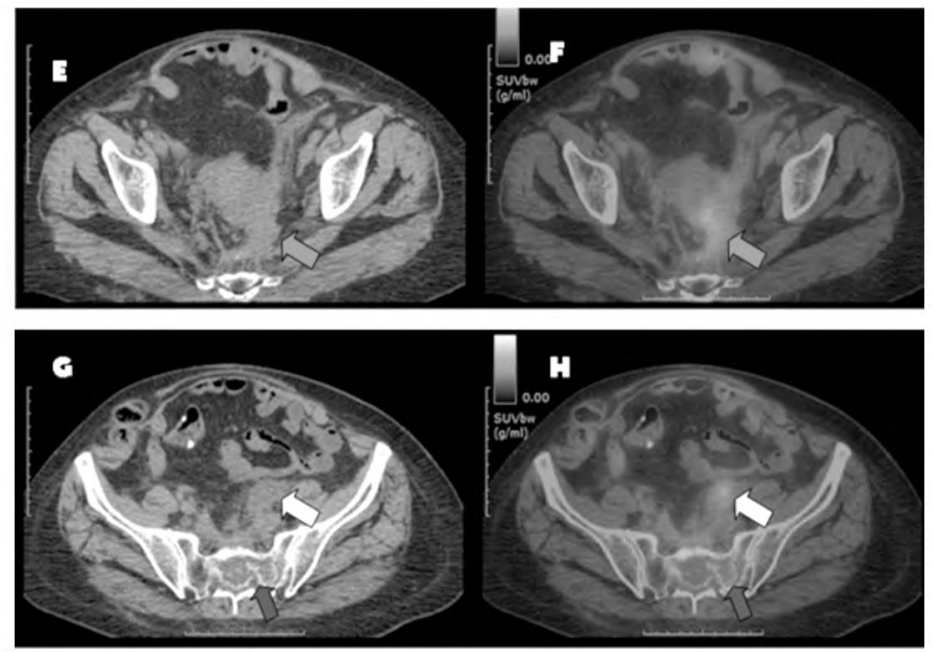

Fig. (1): Axial CT and fused PET-CT images of A 62-year old female patient presented with a history of cancer rectum for which she had an operation followed by chemotherapy.

The baseline study was in 9/2018:

- Images A and B showed an operative bed deep pelvic left side ill-defined soft tissue lesion (red arrow) measuring 4.5 X $3.5 \mathrm{~cm}$. In CT, it might represent post-operative scarring or recurrent neoplastic mass lesion, but it shows an increased FDG uptake with SUV max $=6.1$ denoting a recurrent neoplastic lesion, and this was confirmed by histopathological examination.

- Images $\mathrm{C}$ and $\mathrm{D}$ showed a hypermetabolic metastatic left external iliac lymph node (yellow arrow) measuring $1.6 \mathrm{~cm}$ and shows $\mathrm{SUV}$ max $=8.1$, moreover, a metastatic sacral metabolically active osteolytic lesion (blue arrow) that is measuring $6 \mathrm{X} 4 \mathrm{~cm}$ with SUV max=14 is also demonstrated.

The follow-up study was in 12/2018:

- Images $\mathrm{E}$ and $\mathrm{F}$ showed morphological and metabolic regression of the operative bed hypermetabolic recurrent soft tissue lesion (red arrow) showing SUV max 4.1.

- Images $\mathrm{G}$ and $\mathrm{H}$ showed morphological and metabolic regression of the metastatic left external iliac lymph node (yellow arrow) showing SUV max 2. They also showed marked metabolic regression of the sacral osteolytic lesion (blue arrows) with SUV max $=3.6$ with regressive morphologic course with evident sclerosis (healing) and decreased extra-osseous pre-sacral soft tissue component as well as the intra-sacral component.

$6 / 2018$
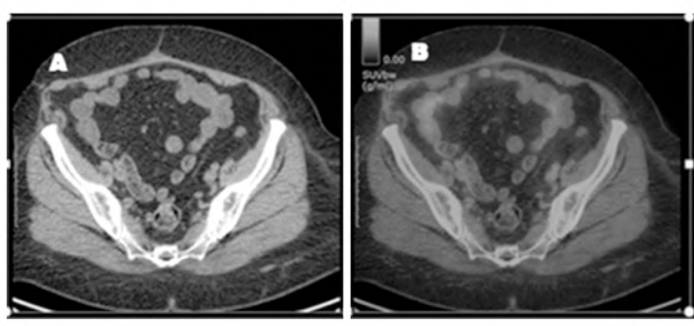

$9 / 2018$
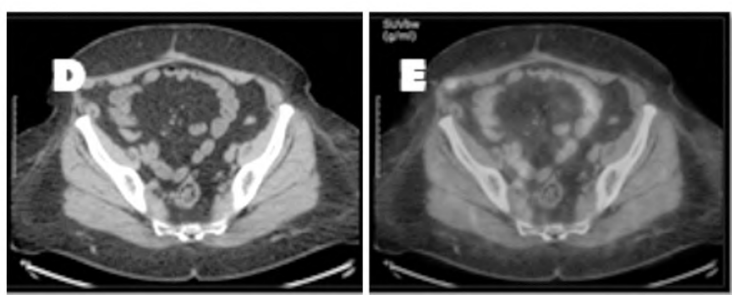
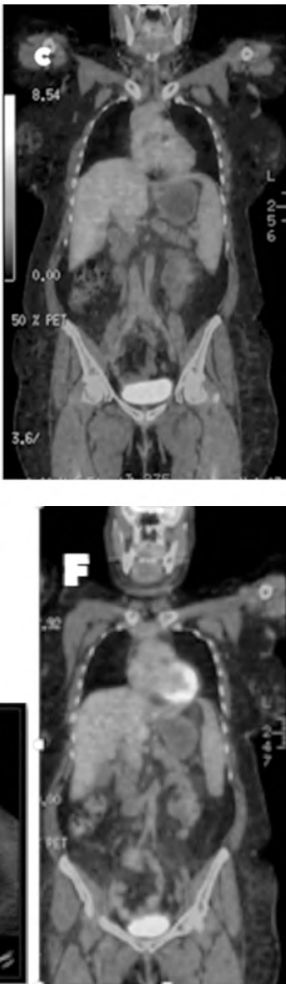

Fig. (2): Axial CT and axial and coronal fused PET-CT images for a 50-year old female patient presented with a history of sigmoid colon cancer for which she had an operation followed by chemotherapy.

The baseline study was in 6-2018:

- Images A and B showed no evidence of metabolically active loco-regional residual/recurrent lesions.

- Image $\mathrm{C}$ showed no distant metastatic lesions.

The follow-up study in 9-2018:

- Images D and E showed a rather stationary course and still no metabolically active loco-regional residual/recurrent lesions.

- Image F showed a stationary course and still no distant metastatic lesions. 

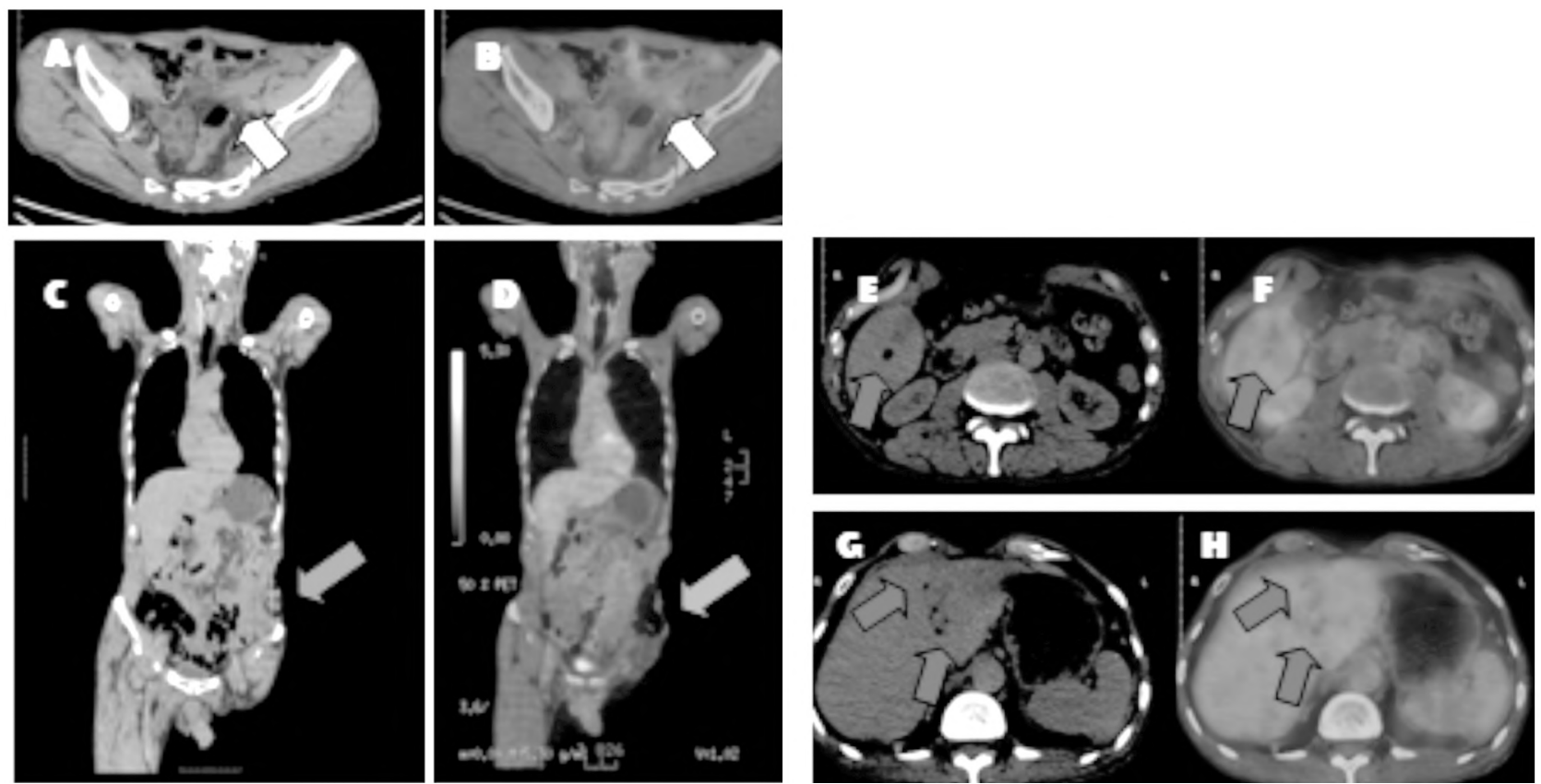

Fig. (3): Axial and coronal CT and fused PET-CT images for a 70-year old male patient presented with a history of sigmoid cancer colon, for which he had sigmoidectomy with pathological diagnosis of infiltrating adenocarcinoma grade II, then he had received chemotherapy.

- Images A, B, C, and D showed clear colectomy (yellow arrow) and colostomy (red arrow) operative bed with no abnormal FDG uptake denoting no residual or recurrent loco-regional neoplastic lesions.

- Images E, F, G, and H showed few right hepatic lobe hypodense focal lesions that are suggestive of the metastatic process in CT. Yet, they showed no significant FDG uptake denoting the absence of tumor activity. The largest lesion is seen in segment VI and is measuring about $12 \mathrm{~mm}$
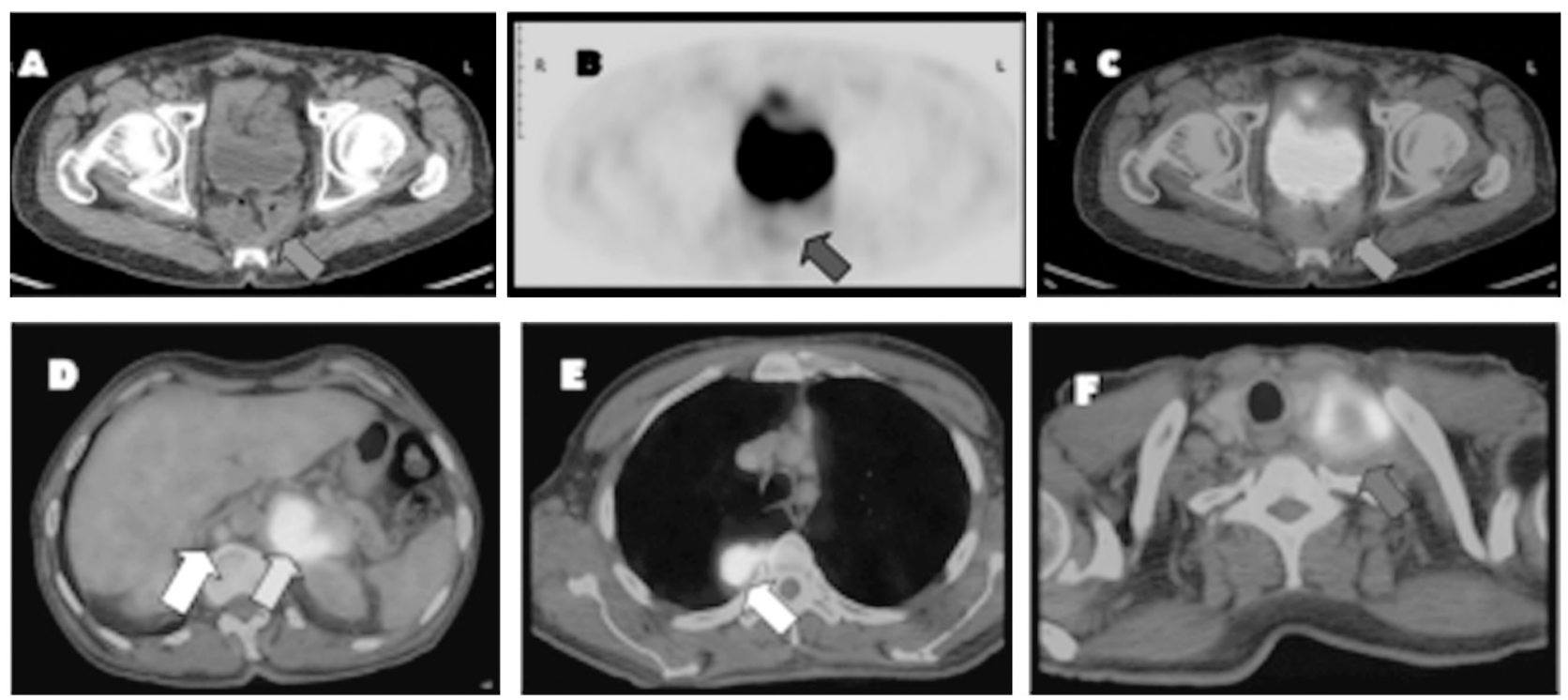

Fig. (4): Axial CT, PET, and fused PET-CT images for a 75-years old male patient with a history of the anorectal tumor. The patient underwent surgical resection and received chemotherapy.

- Images A, B, and C showed irregular pre-sacral soft tissue density in the operative bed suggesting a tumor recurrence; yet, it shows no gross FDG uptake denoting a post-operative scarring (red arrow).

- Image D showed metabolically active metastatic left adrenal mass lesion (green arrow) measuring $6.3 \mathrm{~cm}$ in its maximum dimensions with SUV max=9.6. It also showed metabolically active metastatic right retro-crural lymph node (white arrow) measuring $14 \mathrm{X} 19 \mathrm{~mm}$ in its maximum dimensions with SUV max=3.2.

- Image $\mathrm{E}$ shows hypermetabolic metastatic right upper lobar posterior segment subpleural pulmonary mass (yellow arrow) measuring $2.8 \mathrm{X}$ $3.7 \mathrm{~cm}$ with SUV max=11.6.

- Image F showed metabolically active metastatic left supra-clavicular nodal mass (blue arrow) measuring $5 \mathrm{~cm}$ in its maximum dimension with SUV max=7.7. 

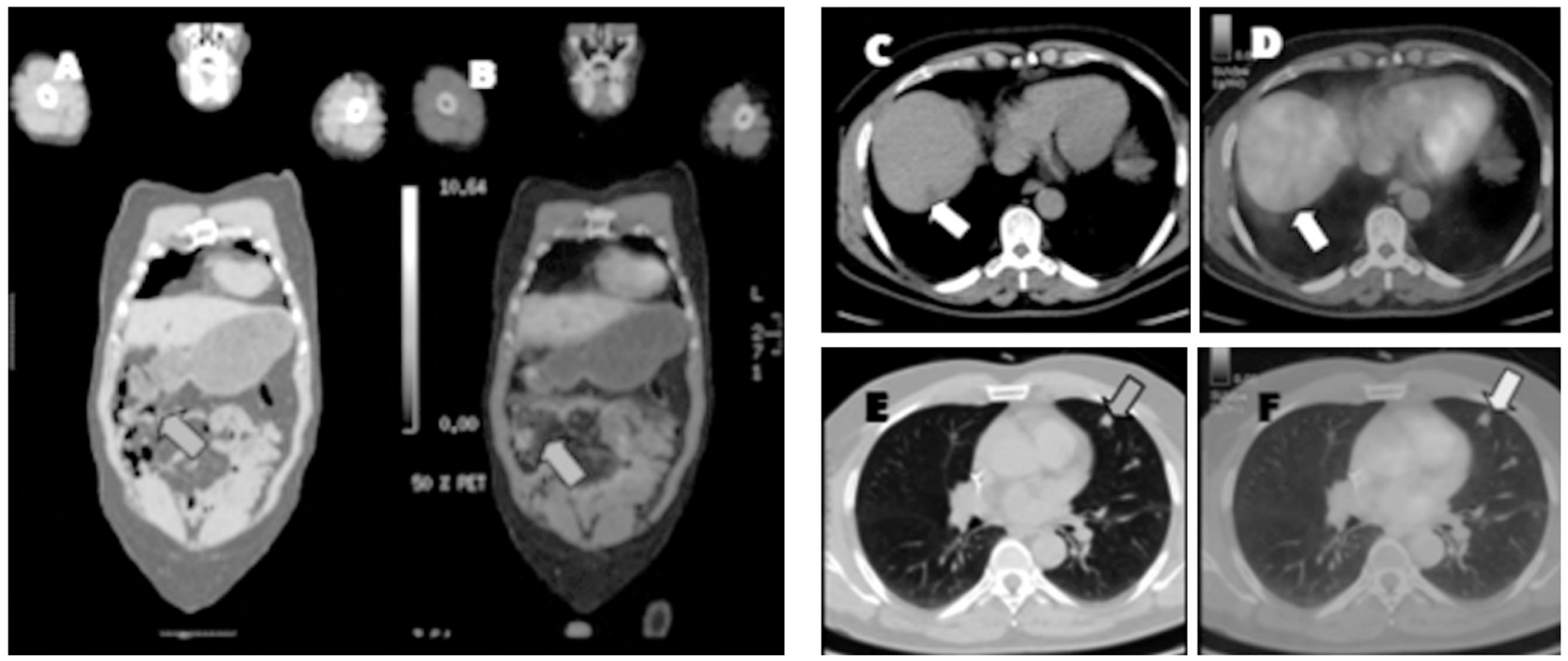

Fig. (5): Coronal and axial CT and fused PET-CT images for a 50-year old male patient diagnosed with colonic hepatic flexure infiltrating adenocarcinoma for which he had a right hemicolectomy followed by chemotherapy.

- Images A and B showed a clear operative bed with no gross hypermetabolic mass lesions (red arrows).

- Images $\mathrm{C}$ and D showed right hepatic lobe (segment VIII) hypodense focal lesion that is noted in CT but shows no FDG uptake denoting the absence of tumor activity (yellow arrows).

- Images E and F showed left lung pulmonary nodule that is noted in CT but shows no FDG uptake denoting the absence of tumor activity (green arrows).

$8 / 2018$
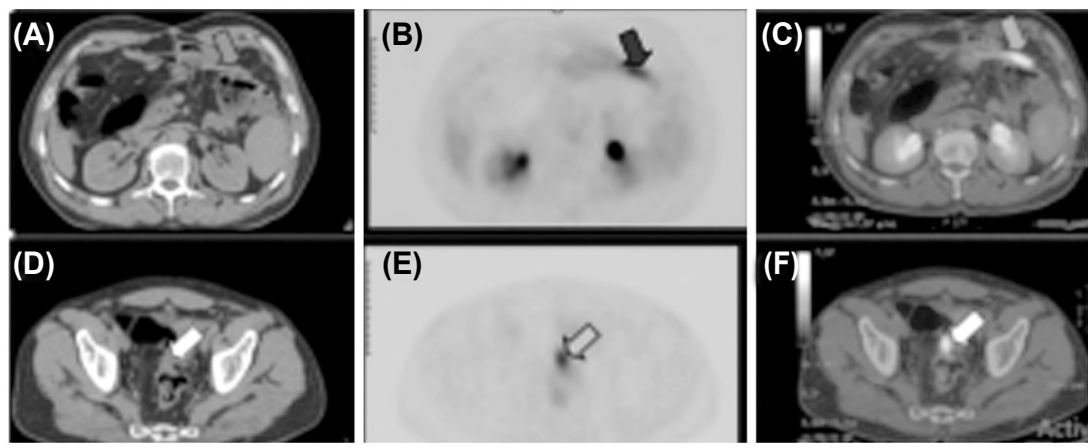

$12 / 2018$
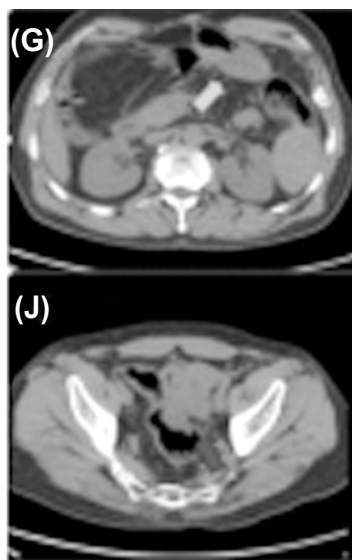

(H)

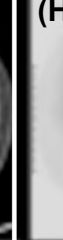

(K)

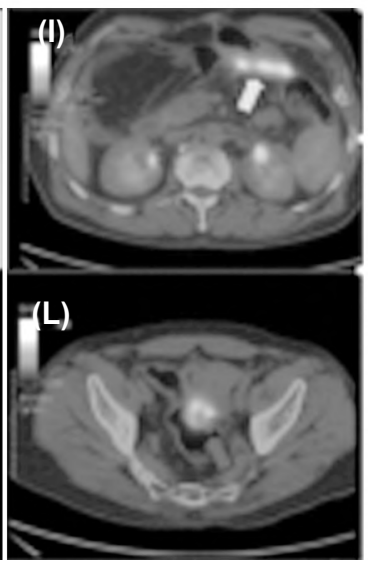

Fig. (6): Axial CT, PET, and fused PET-CT images for a 52-year old male patient presented with transverse colon cancer. He underwent surgical resection and then received chemotherapy.

The baseline study was in 8/2018:

- Images A, B, and C showed increased FDG uptake (SUV max=6) by thin soft tissue sheet related to the greater curvature of the stomach (red arrows), denoting a peritoneal deposit. It was missed in CT.

- Images D, E, and F showed increased FDG uptake (SUV max $=6.9$ ) by small soft tissue nodule that is related to the sigmoid colon (yellow arrows) denoting a peritoneal deposit. It was also missed in CT.

The follow-up study was in 12/2018:

- Images G, H, and I show the metabolic and morphological progressive course of the peritoneal deposit that is related to the greater curvature of the stomach (green arrows) showing SUV max 10.2.

- Images J, K, and L showed metabolic and morphological progressive course of the peritoneal deposit that is related to the sigmoid colon (blue arrows) showing SUV max 14.9 . 


\section{Discussion}

Colorectal cancer is the third leading cause of death worldwide with a relatively high recurrence rate that has been reported in up to one-third of the treated cases; nevertheless, the recurrence patterns could be a loco-regional, nodal or distant metastatic disease. As the recurrent disease is potentially curable in certain cases, the restaging of the recurrence was mandated, and a highly sensitive imaging modality is needed [18-20].

The follow-up methods are quite variable including laboratory studies (tumor markers), endoscopy, and the conventional imaging studies like CT and MRI; however, the lack of a standardized imaging protocol and the reported low sensitivity in the differentiation between the tumor tissue and the post-operative sequelae of intervention has greatly limited the use of such modalities. Moreover, a certain size of the tumor recurrence is required to be assessable and measurable by using these modalities [21,22]

As the conventional CECT may provide useful data about the anatomical and the morphological aspects of the tumor recurrence, the metabolic activity of the tumor cells could also be assessed by FDG PET, thus an integration of their images as fused PET/CT system allows an optimum coregistration of the images with more accurate results than side by side interpretation [5-12,23]

In line with the findings of previous studies [24-28], we have reported tumor recurrences in the operative bed; nodal metastases, distant organ metastases, and peritoneal seeding. Ries et al., [26] described the rectosigmoid region as the commonest location for operative bed recurrence, which matches our findings where the rectosigmoid region being affected in 31 patients (36.9\%). As we have reported the disease recurrence in three categories, the operative bed recurrence was present in 60 patients $(71.4 \%)$, nodal metastases were present in 30 patients $(35.7 \%)$, and distant metastases were present in 26 patients (30.9\%); these findings match those of studies conducted by Hussein and Nassef [25] and Chiewvit et al., [27] who documented a recurrence rate of over $70 \%$.

In reference to the histopathology results, clinical and radiological follow-up assessments and the tumor markers (if available), the accuracy measures in our study are in a concordance with those by the studies $[\mathbf{2 5 , 2 6 , 2 9 , 3 1 ]}$

The false-positive results given by the CECT may lead to a clinical conflict, especially if the patient's laboratory findings are discordant, necessitating a biopsy for the suspicious soft tissue masses. In this way, the fused PET/CT adds great value in this regard and could mitigate the issue (the negative predictive value was $83.33 \%$ in our study) as it assesses the metabolic activity in the soft tissue masses for detection of the viable tumor cells with high metabolic activity and the sterile masses with no tumor activity that may represent otherwise scar or operative bed granulation tissues Fig. (4).

We had false-positive results by fused PET/CT for operative bed recurrent tissues in four of our cases $(4.7 \%)$ proved to be negative for tumor cells by the histopathology examination (the gold standard reference in the study for the operative bed recurrence), also the tumor markers follow-up for these cases supported the pathology results in terms of the decline in the tumor marker levels, and the metabolic activity in the suspected lesion was no longer seen in the follow-up imaging; these findings align with those by Rodríguez-Vigil et al., [30] and other studies [32-34] which indicate that the 18FFDG could be taken up by both malignant and inflammatory cells.

However, the accuracy measures for the detection of the nodal and the distant metastases were not conducted in the current study as the histopathology reference was not available for the nodal and the metastatic lesions, and therefore their assessment was based on the morphological and the metabolic activity for any suspicious lesion as well as its therapeutic response on the follow-up studies and the decline in the CEA levels. The reference standards for the nodal and distant metastatic lesions were the clinical, radiological followup and the tumor marker levels as the need for a biopsy from a metastatic lesion is not accepted in the clinical practice except if there was an absolute indication.

For the nodal metastasis, our study has revealed nodal affection by PET/CT in 30 cases $(35.7 \%)$ that were predominantly abdominal in location (22 cases; $26.2 \%$ ) followed by the mediastinal nodes ( 6 cases; $7.14 \%$ ) then by the cervical nodes ( 3 patients; $3.6 \%$ ). Such findings agree with those from Taha Ali study [24] as well as those from Hussein and Nassef's study [25] regarding the detection of the metabolically active lymph glands shown by follow-up and by the tumor markers as malignant nodes with a therapeutic response to the chemotherapy. 
Hence, the fused PET/CT adds a diagnostic value for detection of the metabolically active metastatic lymph glands with a better anatomical localization than the size-based CT detection when used solely.

Regarding the distant metastases, they were ordered sequentially as hepatic, pulmonary, peritoneal, bone, and atypical site metastases $(22,11$, $3,2 \& 1$ cases respectively). Regarding the detection of the distant metastatic lesions and the peritoneal seeding by the PET/CT, a concordance with the findings from Taha Ali [24], Hussein and Nassef [25], Chalabi et al., [31], Chen et al., [35] and Choi et al., [36] studies is present.

Through the assessment of the FDG avidity, hepatic and pulmonary metastases were excluded in some of the cases Figs. $(3,5)$. Also detection of such FDG avidity showed metastatic affection Fig. $(1,4,6)$, which was correlated to the clinical, radiological follow-up studies and to the tumor marker levels as well. These finding match those from $[25,26,36,37]$ studies that have highlighted a high sensitivity of the fused PET/CT for depiction of distant metastatic diseases and peritoneal seeding.

The atypical distant metastasis was present in only one case (1.2\%) of our study, seen in the left adrenal gland Fig. (4). This finding concurs with those from Ouchi et al., [37] who describes atypical sites of metastases that are infrequently depicted like metastases to the spleen, biliary system, pancreatic, peripancreatic LN, adrenals, mammary, gonadal, cutaneous, umbilical, and oral and the vagina cavities.

\section{Conclusion:}

In summary, the current study has shown that fused PET/CT may be more effective than CECT regarding the detection of operative bed recurrent disease and incomplete therapeutic responses (residuals) for the treated cases of colorectal cancers, with a potentiality to be the modality of choice. Besides, PET/CT could offer a cost-effective wholebody scan to restage the recurrent diseases through a precise detection of the nodal and distant metastases.

\section{References}

1- ELIAS D., SIDERIS L., POCARD M., et al.: Results of $\mathrm{R} 0$ resection for colorectal liver metastases associated with extrahepatic disease. Ann. Surg. Oncol., 11: 274-80, 2004.

2- CHEN L.B., TONG J.L., SONG H.Z., et al.: (18) F-DG $\mathrm{PET} / \mathrm{CT}$ in detection of recurrence and metastasis of colorectal cancer. World J. Gastroenterol., 13: 5025-9, 2007.
3- PFANNSCHMIDT J., BISCHOFF M., MULEY T., et al.: Diagnosis of pulmonary metastases with helical CT: The effect of imaging techniques. Thorac. Cardiovasc. Surg., 56: 471-5, 2008.

4- WIERING B., RUERS T.J., KRABBE P.F., et al.: Comparison of multiphase CT, FDG-PET and intra-operative ultrasound in patients with colorectal liver metastases selected for surgery. Ann. Surg. Oncol., 14: 818-26, 2007.

5- ARULAMPALAM T., COSTA D., VISVIKIS D., et al.: The impact of FDG-PET on the management algorithm for recurrent colorectal cancer. Eur. J. Nucl. Med., 28: 1758-65, 2001.

6- HEUSNER T., HAHN S., HAMAMI M., et al.: Gastrointestinal 18F-FDG accumulation on PET without a corresponding CT abnormality is not an early indicator of cancer development. Eur. Radiol., 19: 2171-9, 2009.

7- TEREZAKIS S. and YAHALOM J.: PET-computed tomography for radiation treatment planning of lymphoma and hematologic malignancies. PET Clin., 6: 165-75, 2011.

8- ENGLEDOW H., BOND-SMITH G., FRANCIS D., et al.: The incremental value of dual-modality PET/CT imaging over PET imaging alone in advanced colorectal cancer. Indian J. Surg., 71: 63-8, 2009.

9- ENDO K., ORIUCHI N., HIGUCHI T., et al.: PET and PET/CT using 18F-FDG in the diagnosis and management of cancer patients. Int. J. Clin. Oncol., 11: 286-96, 2006.

10- SCHULTHESS G.K., STEINERT H.C. and HANY T.F.: Integrated PET/CT: Current applications and future directions. Radiology, 238: 405-22, 2006.

11-ELL P.J.: The contribution of PET/CT to improved patient management. Br. J. Radiol., 79: 32-6, 2006.

12- KANTOROVA I., LIPSKA L., BELOHLAVEK O., et al.: Routine (18) F-FDG PET preoperative staging of colorectal cancer: Comparison with conventional staging and its impact on treatment decision making. J. Nucl. Med., 44: 1784-8, 2003.

13- SCOTT A.M., GUNAWARDANA D.H., KELLEY B., et al.: PET changes management and improves prognostic stratification in patients with recurrent colorectal cancer: Results of a multicenter prospective study. J. Nucl. Med., 49: 1451-7, 2008.

14- BRUSH J., BOYD K., CHAPPELL F., et al.: The value of FDG positron emission tomography/computerized tomography (PET/CT) in pre-operative staging of colorectal cancer: A systematic review and economic evaluation. Health Technol. Assess., 15: 1-192, 2011.

15- KAPOOR V., Mc COOK B.M. and TOROK F.S.: An introduction to PET/CT Imaging. Radio Graphics, 24: 523-54, 2004.

16- GALEN R. S.: Predictive values and efficiency of laboratory testing. Pediat. J. Clin. North Am., 27: 861-9, 1980.

17- JADVAR H. and PARKER J.: PET Physics and Instrumentation. In: Clinical PET and PET/CT, Jadvar H \& Parker J. eds. Springer-Verlag London Limited, 1: 1-44, 2005.

18- HILLNER B.E., SIEGEL B.A., LIU D., et al.: Impact of PET/CT and positron emission tomography (PET) alone on expected management of patients with cancer: Initial 
results from the national oncologic PET registry. J. Clin. Oncol., 26: 2155-61, 2008.

19- KHATRI V.P., CHEE K.G. and PETRELLI N.J.: Modern multimodality approach to hepatic colorectal metastases: Solutions and controversies. Surg. Oncol., 16: 71-83, 2007.

20- HERBERTSON R.A., SCARSBROOK A.F., LEE S.T., et al.: Established, emerging and future roles of 18FDG PET-CT in the management of colorectal cancer. Clin. Radiol., 64: 225-37, 2009.

21- KAMEL I.R., COHADE C., NEYMAN E., et al.: Incremental value of CT in PET/CT of patients with colorectal carcinoma. Abdom. Imaging, 29: 663-8, 2004.

22- POEPPEL T., KRAUSE B., HEUSNER T., et al.: PET/CT for the staging and follow-up of patients with malignancies. European Journal of Radiology, 70: 382-92, 2009.

23- WILLIAM E. and CLYDE A.: Fundamentals of diagnostic radiology. Book, p. 850-6, 2007.

24- TAHA ALI T.: Usefulness of PET-CT in the assessment of suspected recurrent colorectal carcinoma. The Egyptian Journal of Radiology and Nuclear Medicine, 43 (2), pp. 129-37, 2012.

25- HUSSEIN A. and NASSEF M.: Assessment of postoperative local and distant recurrence in colorectal cancer patients: Comparison between PET/CT and CECT. The Egyptian Journal of Radiology and Nuclear Medicine, 47 (2), pp. 431-8, 2016.

26- RIES L.A.G., YOUNG J.L., KEEL G.E., et al.: Editors. SEER Survival Monograph: Cancer Survival Among Adults: U.S. SEER Program, 1988-2001, Patient and Tumor Characteristics. National Cancer Institute, SEER Program, 2007.

27- CHIEWVIT S., JIRANANTANAKORN T., APISARNTHANARAK P., et al.: Detection of recurrent colorectal cancer by $18 \mathrm{~F}-\mathrm{FDG}$ PET/CT comparison with contrastenhanced CT scan. J. Med. Assoc. Thai., 96 (6): 703-8, 2013.

28- CHOWDHURY F.U., SHAH N., SCARSBROOK A.F., et al.: [18F] FDG PET/ CT imaging of colorectal cancer: A pictorial review. Postgrad Med. J., 86: 174-82, 2010.

29- HEBERTSON R.A., SCARSBROOK A.F., LEE S.T., et al.: Established, emerging and future roles of PET/CT in the management of colorectal cancer. Clin. Radiol., 64: 225-37, 2008

30- RODRIGUEZ-VIGIL B., GOMEZ-LEON N., PINILLA I., et al.: PET/CT in lymphoma: Prospective study of enhanced full-dose PET/CT versus unenhanced low-dose PET/CT. J. Nucl. Med., 47: 1643-8, 2006.

31- CHALABI N.A.M., BASSIOUNY R.H. and EL SEDEK M.A.: FDG-PETCT versus contrast-enhanced computed tomography in diagnosis of post-therapeutic colorectal cancer recurrence and metastases. Egypt J. Radiol. Nucl. Med., 51, 3, 2020.

32- GUTMAN F., ALBERINI J., WARTSKI M., et al.: Incidental colonic focal lesions detected by FDG PET/CT. A.J.R. Am. J. Roentgenol., 185: 495-500, 2005.

33- KONISHI J., YAMAZAKI K., TSUKAMOTO E., et al.: Mediastinal lymph node staging by FDG-PET in patients with non-small cell lung cancer: Analysis of false-positive FDG-PET findings. Respiration, 70: 500-6, 2003.

34- RIOPEL M., KLIMSTRA T. and GODELLAS C.V.: Intrabiliary growth of metastatic colonic adenocarcinoma. A pattern of intra-hepatic spread easily confused with primary neoplasia of the biliary tree. Am. J. Surgical Pathology, 21: 1036, 1997.

35- CHEN L.B., TONG J.L., SONG H.Z., et al.: (18)F-DG PET/CT in detection of recurrence and metastasis of colorectal cancer. World J. Gastroenterol., 13: 5025-9, 2007.

36- CHOI E.K., YOO L.R., HAN E.J., et al.: Value of surveillance F-18 FDG PET/CT in colorectal cancer: Comparison with conventional imaging studies. J. Nucl. Med., 51 (2 Suppl): 1208 [abstract], 2010.

37- OUCHI K., SUGAWARA T. and ONO H.: Histologic features and clinical significance of venous invasion in colorectal carcinoma with hepatic metastasis. Cancer, 78: 231-3, 1996. 


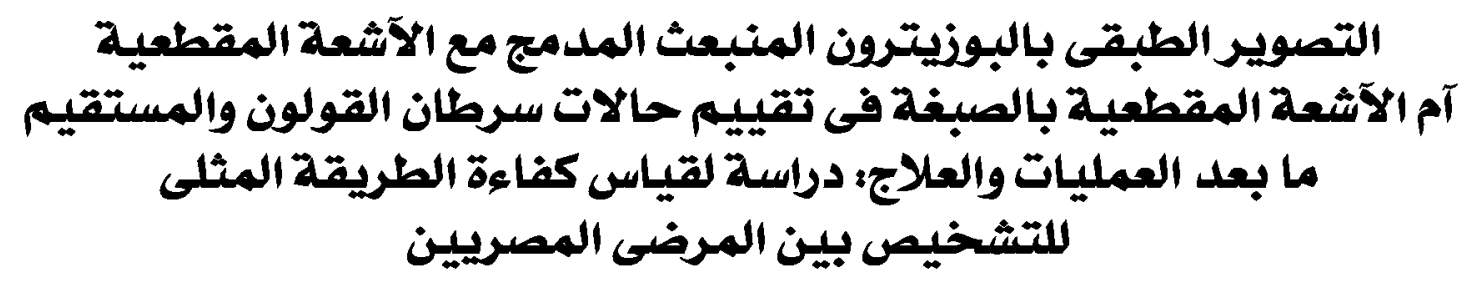

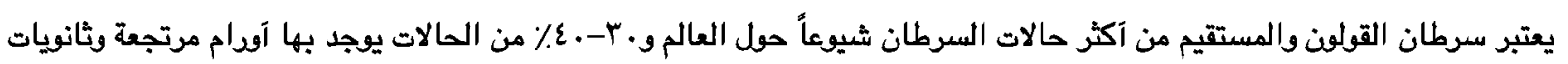

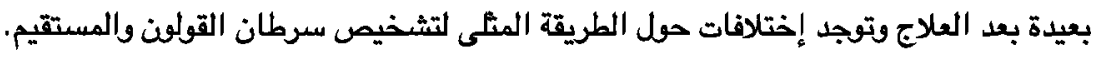

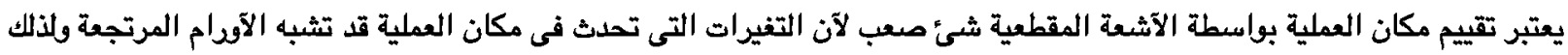

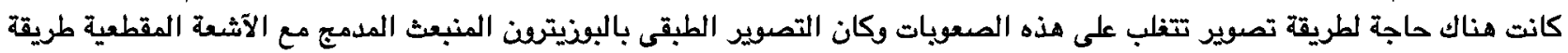

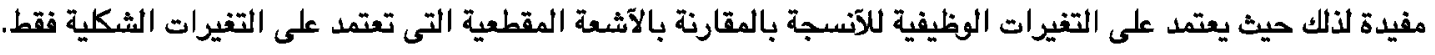
التصوير الطبقى بالبوزيترين المنبعث المدمج مع الآثعة المقطعية مفيد آيضاً فى إكتشاف ثانويات العقد الليمفاوية والثانويات البعيدة فى

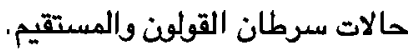

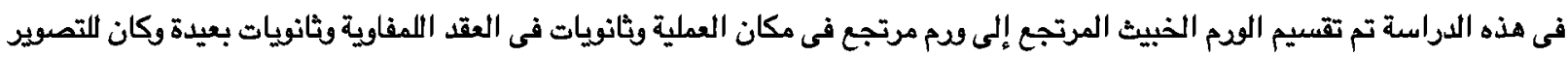

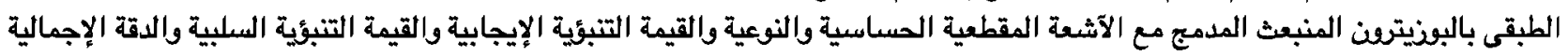
بقيم آفضل من الآشعة المقطعية. ولذلك يعتبر التصوير الطبقى بالبوزيترن المنبعث المدمج مع الآثعة المقطعية آداة مفيدة فى تقييم حالات سرطان القولمن والمستقيم بعد العمليات والعلاج. 